\title{
Erratum to: Efficacy and Safety of the PCSK9 Inhibitor Evolocumab in Patients with Mixed Hyperlipidemia
}

\author{
Robert S. Rosenson ${ }^{1}$ - Terry A. Jacobson ${ }^{2}$ • David Preiss ${ }^{3} \cdot$ Stephen C. Djedjos $^{4}$ • \\ Ricardo Dent $^{5} \cdot$ Ian Bridges $^{6} \cdot$ Michael Miller $^{7}$
}

Published online: 6 August 2016

(C) Springer Science+Business Media New York 2016

Erratum to: Cardiovasc Drugs Ther (2016) 30:305-313

DOI 10.1007/s10557-016-6666-1

The original version of this article unfortunately contained a mistake. In the Results of the Abstract section, where it says "...compared to $-6 \%$ vs. placebo and $-39 \%$ vs. ezetimibe..." it should read "...compared to $-65 \%$ vs. placebo and $-39 \%$ vs. ezetimibe ...".

The online version of the original article can be found at http://dx.doi. org/10.1007/s10557-016-6666-1.

Robert S. Rosenson

robert.rosenson@mssm.edu

Mount Sinai Heart, Cardiometabolics Unit, Icahn School of Medicine at Mount Sinai, 1425 Madison Ave, MC1 Level, New York, NY 10029, USA

2 Emory University, 201 Dowman Drive, Atlanta, GA 30322, USA

3 Clinical Trial Service Unit and Epidemiological Studies Unit, Oxford University, Richard Doll Building, Old Road Campus, Roosevelt Drive, Oxford OX3 7LF, UK

4 Amgen Inc., One Amgen Center Dr, Thousand Oaks, CA 91320, USA

5 Amgen (Europe) GmbH, Dammstrasse 23, 6300 Zug, Switzerland

6 Amgen Ltd, 240 Cambridge Science Park, Milton, Cambridge CB4 0WD, UK

7 University of Maryland School of Medicine, $655 \mathrm{~W}$ Baltimore St, Baltimore, MD 21201, USA 